\title{
Legal Foundations of Funding Fundamental Science Projects within the Horizon Europe Programme
}

\author{
Vitaliy Yu. Slepak, Natalia A. Pozhilova \\ InvestConsult Systems Ltd, Moscow, Russia \\ Event-Lawyers Ltd, Moscow, Russia
}

\begin{abstract}
Since the end of the twentieth century, there has been a trend in Europe towards the accumulation of scientific knowledge, increasing the competitiveness of European research and the mobility of scientists themselves. The goals and objectives set by the European Union are being realised through the creation of a common European Research Area and the implementation of special framework programmes. The EU funding for basic research is now being pursued under a new framework programme known as Horizon Europe. Despite a number of changes caused by the increasing complexity of the structure of the bodies involved in funding research projects, grants to researchers, including through the activities of the European Research Council, remain the main source of investment. Horizon Europe provides research and innovation funding for multinational cooperation projects as well as for individual researchers and supports SMEs with a special funding instrument. Attention should also be paid to such aspects of the programme implementation as European partnerships (in various forms) and research infrastructures. However, despite all the positive experiences of the previous framework programmes, the current legal regulations make it very difficult for researchers from third countries to participate in the call for proposals, usually the possible implementation of such projects is subject to the participation of European researchers or research organisations, thereby ensuring EU competitiveness in the international arena.
\end{abstract}

Keywords: European research area; EU law; European Research Council; Horizon 2020; Horizon Europe; grant funding for science; Megascience; infrastructure; international integration 
Acknowledgements: The work was carried out within the framework of the scientific projects supported by the Russian Foundation for Basic Research (RFBR), projects 18-29-15028 and 18-29-15007. (Topics: "Comparative analysis of best practices in the regulation of grant (project) research and development funding at national and international levels"; "Theoretical and applied research of the legal framework for the construction and operation of unique Megascience facilities in the view of preparation and implementation of the fourth generation Unique Source of Synchrontron Radiation (USSR)").

Cite as: Slepak, V.Yu. and Pozhilova, N.A., (2021). Legal Foundations of Funding Fundamental Science Projects within the Horizon Europe Programme. Kutafin Law Review, 8(3), pp. 423-442, doi: 10.17803/2313-5395.2021.3.17.423-442.

\section{Contents}

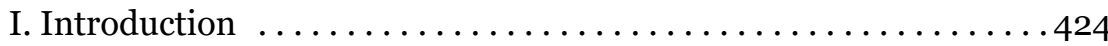

II. The European Partnership ......................... 429

III. The European Innovation Council . . . . . . . . . . . . . 431

IV. The European Research Council (ERC) . . . . . . . . . . . 432

V. The Research Infrastructures . . . . . . . . . . . . . . . 438

References...............................440

\section{Introduction}

Horizon 2020 is to be succeeded in 2021 by the Ninth Horizon Europe programme, which will run from 2021 to 2027. The European Commission's proposal, published on 7 June $2018,{ }^{1}$ aims to address shortcomings in the legal regulation of innovation and improve the financing of research and technological advances and allows the programme achievements to be measured, while ensuring strategic management and budget flexibility.

${ }^{1}$ Proposal for a Regulation of the European Parliament and of the Council establishing Horizon Europe - the Framework Programme for Research and Innovation, laying down its rules for participation and dissemination COM/2018/435 final. Available at: https://eur-lex.europa.eu/legal-content/EN/TXT/?uri=COM\%3A 2018\%3A0435\%3AFIN [Accessed 11.06.2021]. 
The Horizon Europe is the most ambitious programme ever implemented to address societal challenges. Under the long-term budget for 2021-2027 the programme will be allocated around 95.5 billion euros, which is more than the Horizon 2020 budget. Financial rules on the implementation of the Union budget in this field, including the rules on grants, prizes, procurement, indirect management, financial instruments, budgetary guarantees, financial assistance and the reimbursement of external experts are stipulated in the Regulation (EU, Euratom) 2018/1046 of the European Parliament and of the Council of 18 July 2018 on the financial rules applicable to the general budget of the Union. ${ }^{2}$

However, despite the allocated budget, the implementation of the programme is only possible with the implementation of a certain cumulative set of measures, involving all mechanisms, including administrative resources (Archibugi, Filippetti and Frenz, 2020, p. 17).

The main objectives of the Ninth Framework Programme include:

- Increasing innovation capacity, competitiveness and jobs in the European Union and EU Member States;

- Strengthening the EU's science and technology base;

- Realization of the priorities of the EU citizens and upholding values.

This approach allows "all social actors (researchers, citizens, policymakers, business, third sector organisations, and others) cooperate to align the innovation process and its outcomes with societal expectations and values" (Cozzoni, Passavanti, Ponsiglione, Primario and Rippa, 2021, p. 1).

Like all previously implemented framework programmes, Horizon Europe has a complex structure and it is a whole system of different bodies and subprogrammes, which can be roughly divided into several constituent elements.

${ }^{2}$ Regulation (EU, Euratom) 2018/1046 of the European Parliament and of the Council of 18 July 2018 on the financial rules applicable to the general budget of the Union, amending Regulations (EU) No 1296/2013, (EU) No 1301/2013, (EU) No 1303/2013, (EU) No 1304/2013, (EU) No 1309/2013, (EU) No 1316/2013, (EU) No 223/2014, (EU) No 283/2014, and Decision No 541/2014/EU and repealing Regulation (EU, Euratom) No 966/2012 OJ L 193, 30.07.2018, pp. 1-222. Available at: https://eur-lex.europa.eu/legal-content/EN/TXT/?uri=uriserv\%3AOJ. L_.2018.193.01.0001.01.ENGandtoc $=$ OJ\%3AL\%3A2018\%3A193\%3ATOC [Accessed 11.06.2021]. 
More generally, Horizon Europe shall be implemented through 1) the Framework Programme for Research and Innovation, ${ }^{3}$ 2) a financial contribution to the European Institute of Innovation and Technology and 3) the specific programme on defence research - European Defence Fund. ${ }^{4}$ Thus Horizon Europe integrated defence research programmes into general framework of European research area.

Equally important changes concern additional actions that support the three main Special Programmes aimed at widening the participation and reforming and strengthening the systems already in place in the European Union.

Widening the participation and strengthening the European Research Area will take place through the increased support to the European Union Member States, in particular their promotion of maximizing national research and innovation potential, as well as closer cooperation and dissemination of best practices.

Unlike Horizon 2020 Horizon Europe states that there are nonEuropean Union countries who will be able to participate. However, it is noteworthy that the procedure for selecting participants is not simplified. On the contrary, it has been made more complicated in order to establish certain privileges for the EU Member States. It is assumed that applicants with good science, technology and innovation potential will be able to take part in grant funding under the current programme, but due to the new conditions this objective becomes difficult to achieve for third-country nationals.

In the new European Framework Programme there are two ways of obtaining a grant: joint research funding and individual participation. To apply for funding under the first option (joint research), it is necessary to team up with organizations from at least three other EU Member

3 Council Decision (EU) 2021/764 of 10 May 2021 establishing the Specific Programme implementing Horizon Europe - the Framework Programme for Research and Innovation, and repealing Decision 2013/743/EU OJ L 167I, 12.05.2021, pp. 1-8o. Available at: https://eur-lex.europa.eu/legal-content/EN/TXT/?uri=CELE X\%3A32021Do764andqid=1624178185784 [Accessed 11.06.2021].

4 Regulation (EU) 2021/697 of the European Parliament and of the Council of 29 April 2021 establishing the European Defence Fund and repealing Regulation (EU) 2018/1092 OJ L 170, 12.05.2021, pp. 149-177. Available at: https://eur-lex.europa. $\mathrm{eu} /$ legal-content/EN/TXT/?uri=CELEX\%3A32021Ro697andqid=16241801570 51 [Accessed 11.06.2021]. 
States or associated with the Horizon Europe programme, where one of the countries must be an EU Member State. There is an opinion that if the non-EU partner is funded by national sources, its attractiveness may increase, as the consortium will benefit from its expertise without requesting more EU funding. This effect is expected to be significant for "peripheral partners" that do not have a central role in the project, while the more central organizations may be penalized by the "third country status," as they would be less strongly integrated into the project (Cavallaro and Lepori, 2021, pp. 1311-1328).

Funding for individual researchers is provided by the European Research Council (ERC) and the Marie Skłodowska-Curie Programme.

In addition to extending the scope of the programme to more countries, many other adjustments and improvements have also been agreed, including two important noteworthy changes.

The first major change is the updating of partnership approaches, consolidating them into a simple and more effective architecture of three possible forms: jointly programmed, jointly funded and institutionalised. Secondly, it makes it compulsory to publish data produced by the programme in order to find it in the public domain.

The Industrial Leadership Programme aims to make Europe a central player in innovation in the global marketplace. The European Innovation Council is the main implementing body in this area and consequently drives industry and manufacturing in Europe.

In this priority, we saw the biggest change relative to other parts of the programme. Firstly, the very name of the special programme "Industrial Leadership" has been replaced by "Open Innovations," which already implies a fundamental root change in this section. The European Union's industrial leadership has been moved to the third part of the framework programme ("Global Challenges and European Industrial Competitiveness"), which we will discuss later in this paragraph, and replaced by a new theme focused on stimulating and supporting breakthrough innovation to shape the market, where it is assumed that the European Union will surpass other current leaders and take first place in the development, adoption and use of new and emerging technologies. This section consists of three components: European Innovation Council, European Innovation Ecosystems and the 
European Institute of Innovation and Technology (Article 9 of the EU Regulation on the Establishment of the Horizon Europe Programme).

The Priority Axis "Advanced Science" aims at improving the global scientific competitiveness of the European Union. It supports cuttingedge research projects carried out by leading researchers through the European Research Council, funds scholarships for experienced researchers and doctoral students, sponsors exchanges through the Marie Skłodowska-Curie Programme, and invests in world-class research infrastructures.

Beginning with the first special programme, it is worth drawing attention immediately to the difference in categorization of science. Accordingly, advanced science is put in contrast to open science. Apart from the name, the main change here is that emerging and new technologies have been removed from this priority and allocated instead to the other two programmes. The high-priority actions on emerging and new technologies have been moved to the second pillar in the Mission, while the remaining actions on emerging and new technologies have been moved to the third pillar of the framework programme under a new name and with a focus on market breakthrough and disruptive innovations.

Open Science is expected to become critical under the new framework due to its focus on public access to publications. This option makes it easier to track the validity of data generated by researchers, which also contributes to their robust management. This will help market uptake and increase the innovation potential of results from the EU funding.

It is certainly questionable whether these changes should be defined as positive, as full openness of data does not always have a positive impact on the field. In addition, a new generation of criteria and indicators for evaluating research can also be expected in connection with the drive towards publicity.

Otherwise, this special programme remains completely unchanged and continues to focus on scientific excellence through scholarships and research exchanges. 


\section{The European Partnership}

The overall objective of the programme is to ensure the scientific, technological, economic and social impact of the Union's investment in Research and innovation (RandI). This will strengthen the scientific and technological base of the European Union and increase its competitiveness in all Member States. It is proposed to achieve the result through three main areas:

1) accelerating the digitalization of the environment and related issues;

2) increasing resilience and crisis preparedness;

3) supporting Europe's global competitiveness.

Both Horizon 2020 and Horizon Europe consist of three pillars as well as the horizontal action supporting them. However, the latter programme has introduced some changes to address global issues that have long confronted states, academics and society at large.

The European Partnership as a mechanism established under the EU's Ninth Framework Programme, Horizon Europe, can also be considered by its nature as a type of public-private partnership (PPP) designed to bring together the European Commission and private and/ or public partners to address some of the most pressing challenges through concerted research and innovation initiatives. The Regulation defines a European partnership as "an initiative, prepared with the early involvement of Member States and associated countries, where the Union together with private and/or public partners (such as industry, universities, research organisations, bodies with a public service mission at local, regional, national or international level or civil society organisations including foundations and NGOs) commit to jointly supporting the development and implementation of a programme of RandI activities, including those related to market, regulatory or policy uptake.”

5 Regulation (EU) 2021/695 of the European Parliament and of the Council of 28 April 2021 establishing Horizon Europe - the Framework Programme for Research and Innovation, laying down its rules for participation and dissemination, and repealing Regulations (EU) No 1290/2013 and (EU) No 1291/2013. OJ L 170, 12.05.2021, pp. 1-68. Available at: https://eur-lex.europa.eu/legal-content/EN/ TXT/?uri=CELEX\%3A32021R0695 [Accessed 11.06.2021]. 
The aim of the European partnership between the EU and associated countries, the private sector, foundations and other stakeholders is to address global challenges and to modernise industry.

Under the new Horizon Europe programme a European partnership will be maintained with the EU countries, the private sector, foundations and other stakeholders. The aim is to address global challenges and industrial modernization through concerted research and innovation.

The European Horizon sets out the conditions and principles for the establishment of a European partnership and envisages three types (Article 10 of the EU Horizon Europe Regulation):

1. Co-programmed European Partnerships (partnerships between the European Commission and private and/or public partners). These are based on Memoranda of Understanding and/or contractual agreements.

2. Co-funded European Partnerships, using a co-financing programme (partnerships involving EU countries, research sponsors and other public bodies).

3. Institutionalised European Partnerships (bringing together private and public partners).

Clearly, a certain disadvantage of the PPP mechanism is the fact that not all science and technology projects can be commercially and institutionally feasible to implement under this form, because, unfortunately, little-known projects and ideas of innovative, industrial or social orientation cannot be justified in terms of commercial (budgetary) feasibility. Despite the fact that PPPs are one of the effective mechanisms of risk sharing between the state and private investors, most projects are currently not feasible under traditional PPP models (Witters, Marom and Steinert, 2012, pp. 81-87).

A similar point of view is held by V.V. Maksimov who states that "in terms of niche segmentation (target audience) investors in innovation, production and social infrastructure are absolutely different, they are also different at different stages of the life cycle of a PPP project "design - construction - operation" (Maksimov, 2018, pp. 22-27).

For a better understanding of this issue, consider already implemented innovative public-private partnership projects, such as ASAQ Winthrop as a project between the World Health Organization (WHO) and a private company to develop a new antimalarial drug and 
address the challenge of rolling out a programme to use it in the field (Bompart, Kiechel, Sebbag and Pecoul, 2011, p. 143).

Another example is e-Mitra, an agreement between the Government of Rajasthan State of India and local service providers to provide e-services to citizens (e.g., forms, applications, birth certificates, counselling) through specialized centers and local services.

\section{The European Innovation Council}

The European Innovation Council has also been mandated to support creative innovation in order to ensure that Europe remains a strong leader in the global economy (Commission Implementing Decision (EU) 2021/173 of 12 February 2021). ${ }^{6}$

Thanks to the draft programme to date, we can note certain reforms of the existing legal regulation, which will have to be dealt with in the future. For example, the European Innovation Council (EIC) has been created to support innovation, help innovators create markets of the future, attract private funding and also scale up.

It should be noted that the pilot project of the European Innovation Council is already being implemented on the basis of the Eighth Framework Programme and provides funding and opportunities for innovative researchers, innovators and entrepreneurs - often start-ups and companies that differ radically from existing products, services or business models, face a high risk and have the potential for international expansion.

The European Innovation Council pilot project supports ideas from any field of technology or business, including innovative combinations of technologies and business models from the feasibility study to

${ }^{6}$ Commission Implementing Decision (EU) 2021/173 of 12 February 2021 establishing the European Climate, Infrastructure and Environment Executive Agency, the European Health and Digital Executive Agency, the European Research Executive Agency, the European Innovation Council and SMEs Executive Agency, the European Research Council Executive Agency, and the European Education and Culture Executive Agency and repealing Implementing Decisions 2013/801/EU, 2013/771/EU, 2013/778/EU, 2013/779/EU, 2013/776/EU and 2013/770/EU. OJ L 50, 15.02.2021, pp. 9-28. Available at: https://eur-lex.europa.eu/legal-content/en/ TXT/?uri=CELEX:32021D0173 [Accessed 11.06.2021]. 
the development phase, such as innovations in the field of magnetic resonance imaging (MRI), robotics, etc.

By encouraging teams to partner together across the Knowledge Triangle (Research, Higher education and Business) through its KICs and their CLCs, the EIT foster its partnership communities to "cocreate novel innovation approaches." Many of the challenges posed by the European Innovation Council have subsequently become part of the Horizon 2020 (Leceta and Könnölä, 2019, p. 6).

Since March 2019, the Future and Emerging Technologies (FET) programme has been part of an extended pilot project of the EIC. With Horizon Europe's next programme, it is crucial to understand the strengths and weaknesses of the FET and how the programme can evolve, building on the experience of the US Defense Advanced Research Projects Agency (DARPA).

The European Innovation Council and SMEs Executive Agency should ensure a clear focus on innovation and the single market. The European Innovation Council and SMEs Executive Agency should create strong synergies to support the recovery of the European economy, by grouping in one agency all the activities of the EIC and the programme related to small and medium-sized enterprises. The EIC and Interregional Innovation Investments will ensure visibility for innovation, key to supporting the modernisation and sustainability of the EU economy.

\section{The European Research Council (ERC)}

Throughout the process of establishing the European Research Area as what some researchers claim is a "fifth freedom" (Guskova and Sushkova, 2015, pp. 214-223). The need for an independent organisation, based on the basic principles of the European Union and managed by internationally renowned scientists, has been evident throughout the process of shaping the European Research Area, which some researchers argue is developing at this stage in addition to the four existing ones, necessary, among others, for a free movement of research, technology, innovative development and coordination of all 
research activities at both the European and national levels (An ESF position paper, 2003).

The European Research Council (ERC), established in 2007 under the aegis of the implementation of the EU Seventh Framework Programme ${ }^{7}$ is such an organisation. The fundamental aim of the ERC is to support and develop cutting-edge research in Europe, with a focus on creativity and quality. ${ }^{8}$

According to Prof. Bourguignon, the current chair of the ERC, Europe produces a third of the world's new knowledge, but creativity and dynamism in the field must be stimulated. The President of the ERC sees the following as the strategic objective of the organisation, "We created a procedure to support young scientists, which allows us to identify new leaders in research fields and improve career prospects for young researchers. And finally, we wanted to create something completely new for Europe: a standard for research quality and evaluation."

With the establishment in 2013 and the current operation of the Horizon 2020 Framework Programme for Research and Innovation (for the period 2014-2020), the European Research Council exercises powers on the basis of several acts which have made its structure more complex, within the "Quality Science" part of the programme. Thus, the European Research Council currently consists of a Scientific Council and an Executive Agency.

The Scientific Council is made up of twenty-two scientists, whose fields of academic interest lie in various fields, who are of the highest reputation and possess appropriate qualifications, both women and men of different age groups, ensuring a diversity of fields of research and acting in a personal capacity, irrespective of extraneous interests.

7 Regulation (EC) No 1906/2006 of the European Parliament and of the Council of 18 December 2006 laying down the rules for the participation of undertakings, research centres and universities in actions under the Seventh Framework Programme and for the dissemination of research results (2007-2013). OJ L 391, 30.12.2006, pp. 1-18. Available at: https://eur-lex.europa.eu/legal-content/EN/ TXT/?uri=CELEX\%3A32006R1906 [Accessed 11.06.2021].

8 Commission Decision of 2 February 2007 establishing the European Research Council. OJ L 57, 24.02.2007, pp. 14-19. Available at: https://eur-lex.europa.eu/legalcontent/EN/TXT/?uri=uriserv\%3AOJ.L_.2007.057.01.0014.01.ENG\&toc=OJ\%3AL \%3A2007\%3A057\%3ATOC [Accessed 11.06.2021]. 
The members of the Scientific Council are appointed by the European Commission following an independent and transparent selection procedure, including consultation with the scientific community and reports to the European Parliament and the Council, for a term of four years, renewable once to ensure the continuity of the Scientific Council.

The Executive Agency is the administrative body responsible for managing the implementation of the Horizon 2020, including specific projects based on it, and for executing the budgetary authority for the management of all the organisation operations within the programme.

The members of the Executive Agency shall be appointed for a period of up to two years, with the exception of the Director, whose term of office shall be four years, taking into account the opinion of the Scientific Council of the ERC.

All internal structures of the ERC, as well as the organization as a whole, are subject to the control of the European Commission, which, following an audit and performance review of the ERC under the Seventh Framework Programme, noted savings in delegated budgetary and administrative authority of 45 million euros for the organization in the period from 2009 to 2012.

The ERC can establish and maintain a reputation for selecting high-quality "investigator-driven" project proposals only if its processes are transparent, simple, with low administrative burdens and with measurement standards and peer review processes (Follesdal, 2019, pp. 237-247). The applications are selected by independent experts, based on a highly transparent scheme and exclusively on scientific criteria. According to a number of researchers, "this last point is very important, as it distances us from any politically motivated criteria, in particular from the widely used in Europe 'juste retour' principle, according to which each country receives from the pan-European programme in proportion to its own financial contribution."

In evaluating the applications, the European Investment Fund (EIF) does not give preference to any particular field or area of research. Thus, in contrast to previous research funding frameworks, in Horizon 2020 applied research is not explicitly prioritised.

Preference is given, among other equals, to interdisciplinary research containing innovative proposals concerning new areas 
of research or proposals introducing unconventional, innovative approaches to research.

According to the current concept promoted by the ERC, any interested person, regardless of the age and career, is eligible to apply for long-term funding through the ERC grants by submitting an application from anywhere in the world.

ERC funding can be described as a positive sum game: overall, there is a net gain for academic disciplines in participating in the competition for ERC funding, simply because it enables new research avenues and also helps to make them more visible. This is to the advantage of all members of the disciplinary tribe (König, 2019, pp. 248-266).

The funding period is up to five years for the ERC Starting Grant, the ERC Consolidator Grant or the ERC Advanced Grant, and up to seven years for the Synergy Grant.

The amount of funding provided under the grant varies depending on the type of grant and covers up to $100 \%$ of the direct costs and a portion of the indirect costs of $25 \%$ of the direct costs.

The ERC grants are autonomous (transferable) and may, under certain conditions, be transferred, either in part or in full, to another beneficiary. These provisions also cover the conditions for transferring the equipment purchased and used within the grant study in progress to a third party for the project implementation.

Although the ERC is interested in supporting researchers from any country, regardless of the scientist's nationality and in some cases even a research team from another country, the host institution must necessarily be located in the EU or its Associated Members.

The ERC Starting Grant, ERC Consolidator Grant and the ERC Advanced Grant aim at supporting research activities led by a single Principal Investigator, while the Synergy Grant provides funding opportunities for teams of up to four Principal Investigators, correlating obligations to the Team Leader.

The host institution should grant the Principal Investigator a full freedom to carry out the research (including in determining the team of authors and the composition of the publications) and autonomy at the disposal of the grant funds. 
In turn, to ensure the principle of openness of information, the Principal Investigator should ensure that all peer-reviewed research materials, in accordance with the provisions of the Model Agreement on Grant Funding, are made publicly available for re-access by other researchers, with the possibility of subsequent citation.

However, it is worth noting that certain "eligibility criteria" apply to the Lead investigators, depending on the grant funding requested.

The procedures and criteria for evaluating the application submitted by the researcher also vary depending on the type of grant selected.

For the ERC Starting Grant, the ERC Consolidator Grant and the ERC Advanced Grant, there is a two-stage evaluation procedure. In the first stage, only the compliance of the Lead Investigator with the stated "eligibility criteria" is assessed; the "scientific component" of the project is only subject to consideration at the second stage of the evaluation, taking into account the stated project budget, with applicants selected for the second stage being called for interviews directly to the Expert Council meeting in Brussels.

The evaluation procedure for the Synergy Grant application has three steps, including the interview process.

It is important to note that under the terms of the grant, the Principal Investigator is obliged to spend only $50 \%$ of his/her working time in Europe, i.e. there is no need to be permanently present in the EU.

For all applications submitted to the European Research Council, the main and only evaluation criterion is scientific excellence, as demonstrated by the following components: the innovative nature of the research, its ambition, but also its practical feasibility, and the factors confirming the intellectual capacity, creativity and competence of the Principal Investigator.

Projects consisting entirely or to a large extent of the results of comparing and compiling existing materials are less likely to constitute ground-breaking or milestone research and are therefore not recommended for selection by the ERC experts.

In addition to the four main types of grant funding within the ERC, there is now an additional form of research support, namely the ERC Proof of Concept Grant, which is designed for researchers who 
have previously received one of the main grants, but want to assess the commercial potential of the research project, with a direct link to the main research project. The grants are up to 150.000 euros for a period of 18 months.

Given the fact that the European Research Council has been operating within the two Framework Programme for more than ten years now, some researchers have highlighted historically justified perspectives for its future functioning, among them the economic feasibility and effectiveness of delegating authority to the ERC in this area and the institutional-cultural perspective based on strengthening integration processes (Gornitzka and Metz, 2014, pp. 81-110; König, 2017, p. 270).

Dr Barbara Hoenig, analyzing in her studies the impact of the European integration process in research funding, emphasises the following structural changes in the social and institutional organisation of science associated with the European Research Council:

- the formation of new standards for the evaluation of research activities both within and outside the EU;

- creating the ERC as a qualitatively new supranational organisation providing the possibility of obtaining external funding for research activities in the context of reduced public support for universities and individual research institutes;

- individualisation of research funding, based on the identification of leading researchers in each field through the validation of their professional qualifications and reputation with the involvement of independent experts;

- importance of the ERC experience for the formation of similar supranational, global organizations;

- the practical implications associated with a tangible material impact on individual researchers and universities, including in terms of creating a new scientific elite that embodies the "European ideal" (Hoenig, 2017, p. 4).

The special status of the European Research Council as an organisation that operates solely on the basis of opinions expressed by recognised and well-known representatives of the scientific community, and the absence of the need for grant funding of research in proportion 
to the contribution of Member States to the organisation's budget, underlines the inclusive nature of the ERC.

At the end of the Horizon 2020 Framework Programme period the European Research Council will be assessed by the European Commission in terms of the effectiveness of the distribution of the spent budget, but already today we can say that the EU's contribution to research funding is significant.

\section{The Research Infrastructures}

Research infrastructures have become a topic of interest and priority for funders, political bodies, and (increasingly) institutional decision makers. In Europe the European Commission is a funder of RIs, complementing funding done by EU Member States at the national level (Lossau, 2012, pp. 313-329).

The European approach to research infrastructures has made remarkable progress in recent years with the implementation of the European Strategy Forum on Research Infrastructures (ESFRI) roadmap, integrating and opening national research facilities and developing e-infrastructures underpinning a digital European Research Area. The networks of research infrastructures across Europe strengthen its human capital base by providing world-class training for a new generation of researchers and engineers and promoting interdisciplinary collaboration.

Further development and wider use of research infrastructures at the Union level will make a significant contribution to development of the European Research Area. While the role of Member States remains central in developing and financing research infrastructures, the Union plays an important part in supporting infrastructure, fostering the emergence of new facilities, opening up broad access to national and European infrastructures, and making sure that regional, national, European and international policies are consistent and effective. It is not only necessary to avoid duplication of efforts and to coordinate and rationalise the use of the facilities, but also to pool resources so that the Union can also acquire and operate research infrastructures at the world level. 
The efficiencies of scale and scope achieved by a European approach to construction, use and management of research infrastructures, including e-infrastructures, will make a significant contribution to boosting Europe's research and innovation potential.

According to the Regulation, research infrastructures are defined as "research infrastructures" means facilities that provide resources and services for the research communities to conduct research and foster innovation in their fields, including the associated human resources, major equipment or sets of instruments; knowledge-related facilities such as collections, archives or scientific data infrastructures; computing systems, communication networks and any other infrastructure of a unique nature and open to external users, essential to achieve excellence in RandI; they may, where relevant, be used beyond research, for example for education or public services and they may be "single sited," "virtual" or "distributed."

As A.O. Chetverikov points out, "the most common legal category that corresponds to mega-sciences in official documents is the expression 'large research infrastructures', which has also been adopted in Russia." Research infrastructures are facilities that provide resources and services for the research communities to conduct research and foster innovation in their fields.

These include:

- major equipment or sets of instruments;

- knowledge-related facilities such as collections;

- archives or scientific data infrastructures;

- computing systems;

- communication networks.

Horizon Europe will endow Europe with the world class sustainable research infrastructures which are open and accessible to the best researchers from Europe and beyond.

Activities aim at developing the European research infrastructures for 2020 and beyond, fostering their innovation potential and human capital and reinforcing European research infrastructure policy. 


\section{References}

1. An ESF position paper (2003). New structures for the support of high-quality research in Europe. A report from a High Level Working Group constituted by the European Science Foundation to review the option of creating a European Research Council. Available at: https:// erc.europa.eu/sites/default/files/document/file/esf_position_paper. pdf [Accessed 11.06.2021].

2. Archibugi, D., Filippetti, A. and Frenz, M., (2020). Investment in innovation for European recovery: A public policy priority. Science and Public Policy, 47 (1), pp. 92-102, doi: https://doi.org/10.1093/scipol/ sczo49.

3. Bompart, F., Kiechel, J.-R., Sebbag, R. and Pecoul, B., (2011). Innovative Public-Private Partnerships to Maximize the Delivery of Anti-Malarial Medicines: Lessons Learned from the ASAQ Winthrop Experience. Malaria Journal, 10, 143, doi: https://doi.org/10.1186/14752875-10-143.

4. Cavallaro, M. and Lepori, B., (2021). Institutional barriers to participation in EU framework programs: contrasting the Swiss and UK cases. Scientometrics, 126 (2), pp. 1311-1328, doi: https://doi. org/10.1007/s11192-020-03810-0.

5. Chetverikov, A.O., (2018). Organisational and legal forms of big science (mega-sciences) in the context of international integration: a comparative study. Pt. I. Mega-sciences as a scientific and legal phenomenon. Legal aspects of the functioning of Megasciences in the form of international intergovernmental organisations and national legal entities. Yuridicheskaya nauka, (1), pp. 13-27. Available at: http:// jurnauka.ru/upload/iblock/81c/\%E2\%84\%961\%202018.pdf [Accessed 11.06.2021] (In Russ.).

6. Cozzoni, E., Passavanti, C., Ponsiglione, C., Primario, S. and Rippa, P., (2021). Interorganizational Collaboration in Innovation Networks: An Agent Based Model for Responsible Research and Innovation in Additive Manufacturing. Sustainability, 13, 7460, doi: https://doi.org/10.3390/su13137460.

7. Follesdal, A., (2019). The European Research Council @ 10: Whither hopes and fears? European Political Science, 18, pp. 237-247, doi: https://doi.org/10.1057/s41304-018-0163-x.

8. Gornitzka, A. and Metz, J., (2014). Dynamics of Institution Building in the Europe of Knowledge: The Birth of the European Research 
Council. In: M.-H. Chou and Å. Gornitzka (ed.). Building the Knowledge Economy in Europe: New Constellations in European Research and Higher Education Governance, pp. 81-110. Cheltenham: Edward Elgar, doi: https://doi.org/10.4337/9781782545293.00010.

9. Guskova, N.D. and Sushkova, Y.N., (2015). European integration in the context of European studies: realities and prospects. Izvestiya VUZov, Povolzhskij region, Obshchestvennye nauki, 1. Available at: https://izvuz_on.pnzgu.ru/files/izvuz_on.pnzgu.ru/21115.pdf[Accessed 11.06.2021] (In Russ.).

10. Hoenig, B., (2017). Europe's New Scientific Elite: Social Mechanisms of Science in the European Research Area (1st ed.). Routledge, doi: https://doi.org/10.4324/9781315446042. Available at: https:// www.taylorfrancis.com/books/mono/10.4324/9781315446042/europenew-scientific-elite-hoenig-barbara [Accessed 11.06.2021].

11. König, T., (2017). The European Research Council. John Wiley and Sons. 240 p., doi: https://doi.org/10.15203/ozp.1921. vol46iss2. Available at: https://www.wiley.com/en-us/The+European+ Research+Council-p-9780745691244 [Accessed 11.06.2021].

12. König, T., (2019). Political science and the European Research Council. European Political Science, 18, pp. 248-266, doi: https://doi. org/10.1057/s41304-018-0165-8.

13. Leceta, J. and Könnölä, T., (2019). Fostering entrepreneurial innovation ecosystems: lessons learned from the European Institute of Innovation and Technology. Innovation: The European Journal of Social Science Research, pp. 1-20, doi: https://doi.org/10.1080/13511 610.2019.1612737.

14. Lossau, N., (2012). An Overview of Research Infrastructures in Europe - and Recommendations to LIBER. LIBER Quarterly, 21(3-4), pp. 313-329, doi: https://doi.org/10.18352/lq.8028.

15. Maksimov, V.V., (2018). Current legal regulation for attracting private investment in the infrastructure of innovative science and technology centres. Yurist, 10, pp. 22-27 (In Russ.).

16. Witters, L., Marom, R. and Steinert, K., (2012). The role of public-private partnerships in driving innovation. In: Dutta, S. (Ed.), The global innovation index 2012: Stronger innovation linkages for global growth, Fontainebleau, France: INSEAD and World Intellectual Property Organization, pp. 81-87, doi: https://doi.org/ 10.1177/1087724X19847215. 


\section{Information about the Authors}

Vitaliy Yu. Slepak, Head of the Department for Legal Support of Business, InvestConsult Systems Ltd., Moscow, Russia

29-1504 prospect Vernadskogo, Moscow 119331, Russia

v.slepak@consult-systems.ru

Natalia A. Pozhilova, Legal Adviser, Event-Lawyers Ltd., Moscow, Russia 30-6 Shirokaya ulitsa, Moscow 129345, Russia

natalia229@mail.ru 